\title{
Volatility transmission and spillover dynamics across financial markets: the role of geopolitical risk
}

\author{
Ahmed H. Elsayed ${ }^{1,2}$ [D $\cdot$ Mohamad Husam Helmi ${ }^{1}$ (D)
}

Accepted: 15 April 2021 / Published online: 3 May 2021

(c) The Author(s) 2021

\begin{abstract}
This paper examines the effect of geopolitical risk (GPR) on return and volatility dynamics in Middle East and North African (MENA) countries by using an ADCC-GARCH model and a spillover approach. Unlike previous studies, we include the GPR index to capture risk associated with wars, terrorist acts, and political tensions. Moreover, we test for both static and dynamic analysis using a rolling window. In brief, the findings highlight that GPR does not contribute to the return spillovers among MENA financial markets. However, the dynamic analysis provides evidence of the high level of responsiveness of the total spillover index to major political events (e.g., the Arab Spring uprising and political tension between Qatar and other Gulf Cooperation Council countries). More interestingly, Qatar, Kingdom of Saudi Arabia, and the United Arab Emirates are identified as the main transmitters of return spillovers to the rest of the MENA markets. Overall, our results are essential in understanding the impact of the GPR on return spillover among MENA countries, and are of particular importance to policymakers, market regulators, portfolio managers and investors.
\end{abstract}

Keywords Geopolitical risk (GPR) • Volatility transmission · ADCC-GARCH model · Return spillovers $\cdot$ MENA countries

JEL Classification $\mathrm{G} 14 \cdot \mathrm{G} 15 \cdot \mathrm{Q} 41 \cdot \mathrm{C} 51$

\section{Introduction}

Recently, the effect of geopolitical risks on stock market return and volatility has attracted the attention of researchers and policymakers. Geopolitical risks are considered one of the key determinants of investment decisions, which lead to a significant impact on economic growth and the stability of financial markets. Recent literature indicates geopolitical risks

Ahmed H. Elsayed

ahmed.elsayed@durham.ac.uk

$\triangle$ Mohamad Husam Helmi

mohamad.h.helmi@durham.ac.uk

1 Department of Economics and Finance, Durham University, Durham, UK

2 Department of Economics, Faculty of Commerce, Zagazig University, Zagazig, Egypt 
are increasingly shaping economic and financial interactions at both national and international levels (Dogan et al., 2021). According to a Gallup survey in 2017, 75\% of investors who took part declared their concerns about the effect of global military and political conflicts on investments. Significantly, they ranked geopolitical risks (GPR) above economic and political instability. High levels of geopolitical tension are believed to cause a reduction in economic activities, a decline in stock returns, and a redirection of capital outflows from developing countries towards more developed countries (Caldara \& Iacoviello, 2018). Recently, the impact of the geopolitical risks on an economy has been recognised and highlighted by international organisations such as the European Central Bank (ECB) and the International Monetary Fund (IMF). ${ }^{1}$

Geopolitical risk is defined as "the risk associated with wars, terrorist acts, and tensions between states that affect the normal and peaceful course of international relations" (Caldara \& Iacoviello, 2018 p. 6). This definition encapsulates the direct risk that arises from the events listed above as well as any indirect risks resulting from the original incidents, such as a war. The news-based GPR index is derived by counting the occurrence of words related to geopolitical tensions in leading international newspapers (e.g. the New York Times, the Wall Street Journal, and the Financial Times). This newly constructed index is comprehensive and covers various risks that resulted from geopolitical events such as armed conflicts, elections, governmental changes, political upheavals, civil strife, war, and terrorist attacks. This is particularly useful in the context of the Middle East and North Africa (MENA) region that has witnessed several geopolitical turmoil ranging from war and political conflicts (e.g., the Gulf War (1990-1991), the Iraq War (2003-2011), the Arab Spring (2010/2012), Syrian civil war (started in 2011), Qatar diplomatic crisis (2017-2020), to major terrorist attacks. The MENA region has remained the primary theatre for terrorist activities by ISIS and Al-Qaeda over the last decade. Therefore, the existence of geopolitical risks could hinder capital movements and foreign capital inflows into the MENA region, which in turn could result in higher stock market volatility and economic slowdown.

Despite the importance of the topic, empirical evidence is rather limited and overly inconclusive: some studies show a negative impact of geopolitical risks on stock market returns (Caldara \& Iacoviello, 2018); others argue that the relationship depends on the which depend on the volatility regimes, macroeconomic characteristics and levels of stock market development (Hoque \& Zaidi, 2020); and some others do not uncover any impact of geopolitical risks (e.g., Antonakakis et al., 2017; Apergis et al., 2018; Bouras et al., 2019). Furthermore, no previous attempt has been made to examine the impact of geopolitical events on stock market return and volatility in the context of the MENA countries. These countries depend to a great extent on natural resources, and have comparable economic structures, rapid population growth, underdeveloped financial markets and similar political systems that often function differently than those of developed countries. Such circumstances could contribute to a different effect on financial markets, return, and volatility than observed in both emerging and advanced economies. More importantly, the MENA region has faced high levels of political tension from the start of the "Arab Spring" in 2011 (Chau et al., 2014). The lack of empirical studies in the literature is surprising given the proximity of recent political conflicts and the growing importance of the MENA region in the global economy (O'Sullivan et al., 2011).

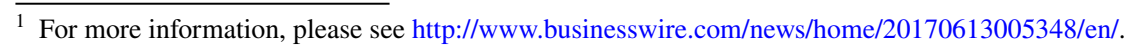


Against this backdrop, this study aims to fill this research gap by making a fourfold contribution. First, it focuses on MENA region, for which very little information is available. Second, contrary to previous literature, it focuses on the impact of GPR on financial interconnectedness between MENA countries. By adopting the Asymmetric Dynamic Conditional Correlation (ADCC-GARCH) model of Cappiello et al. (2006), our paper can measure the dynamic return co-movements, with particular attention to the effects of geopolitical instability and the Arab Spring on financial connectedness. This approach allows us to highlight the key facts related to stock returns in the MENA region, such as volatility clustering, asymmetric volatility and time variation. Third, we extend our analysis further by examining volatility spillover and risk transition on underlying variables using the spillover technique recently developed by Diebold and Yilmaz (2012, 2015). Fourth, our study also contributes to the literature by examining the impact of war, terrorist attacks, GPR, and political events on the economy and stock price (see e.g., Balcilar et al., 2018; Bouras et al., 2019; Chau et al., 2014; Gilpin \& Gilpin, 2001; Glick \& Taylor, 2010; ).

In brief, our analysis reveals that there is very weak or, indeed, no correlation between the GPR index and individual stock returns. This has been confirmed by our spillover analysis in which the GPR index is not shown as a key net transmitter of spillovers to most financial markets in MENA countries. However, GPR was a net transmitter of spillovers to Bahrain, Kuwait, and KSA during major political events such as the Arab Spring uprising in 2010/2011, the Civil War in Yemen (2015-present), the global financial crisis in 2008, as well as the recent political tension between Qatar and other GCC countries. The GCC markets are more connected with each other compared to other MENA markets in our sample, as is evident from the inter-market spillover. Three countries in the GCC, Qatar, KSA, and the United Arab Emirates (UAE), are the main transmitters of return spillovers to the rest of the MENA countries.

The layout is as follows. Section 2 discuss literature review and historical background; Sect. 3 describes the data; Sect. 4 discusses the methodology employed; Sect. 5 presents the empirical findings; finally, Sect. 6 summarises the main results, draws conclusions, and identifies policy implications.

\section{Literature review and historical background}

It is crucial to shed some light on the circumstantial and evolution of the political and civil unrest which remake a significant event in the history of the Arab world and MENA region in particular, but its long-term impact remains unpredictable. Arab spring started when a Tunisia vegetable seller set fire to himself in December 2010 and have since then rapidly spread into the Arab world, namely Egypt, Libya, Yemen and Syria. The uprisings in Tunisia, Egypt and Libya cracked down deep-rooted rulers from power. Further, Bahrain, among the GCC oil-rich countries, was hit by less severe and less persistent protests. Undoubtedly, high level of unemployment, weak economic reforms, and lack of freedom, with corruption skyrocketing are among the main reasons for the uprising (Chau et al., 2014).

Although the Arab spring has given hope for youth in the MENA, this has come with a very high price of significant financial and social costs. The high level of risk associated with this political turmoil has transitory affect the stock market activities, and even deteriorated the economic condition in the MENA region. Further, the GPR could increase volatilities and spillover effect in the stock markets. 
This paper contributes to two strands of literature on market interdependence and risk transmission: (1) the literature on the impact of political uncertainty on stock prices, and (2) the literature on the relationship between the geopolitical risks and stock market returns.

\subsection{Political uncertainty and stock prices}

A great number of empirical studies have examined the impact of political uncertainty on stock price and its volatility. For instance, Alexakis and Petrakis (1991) conducted a broad study of the Greek market and documented a link between the behaviour of the stock market index and political factors. Chan and Wei (1996) showed that favourable political news in Hong Kong produces positive returns, whereas unfavourable news causes negative returns. Further, Perotti and Oijen (2001) examined the effect of political shocks on stock markets in a number of emerging markets. They showed severe fluctuations in excess returns due to an increase or decrease in political risk, which indicates the crucial role of such risks as a pricing factor in a cross-section of stock returns. Pástor and Veronesi (2013) observed high volatility of stock price during a period of high political uncertainty, basing their conclusions on a political uncertainty index, which showed a positive correlation with both the realized and the implied volatility of the S\&P 500 index. Liu et al. (2017) investigated the impact of the Bo Xilai political scandal in 2012 in China. They were able to confirm that political uncertainty had a negative impact on stock price and provided evidence of the existence of priced political risk. Chesney et al. (2011) examined the impact of terrorist attacks on the world economy using data from 25 countries in which 77 terrorist attacks had occurred. They found that there was a negative correlation between such attacks and stock markets. Gozgor (2018) investigated factors of the domestic credits including the role of political risks using a sample of 61 developing economies. Political risk indicators reveal that superior socioeconomic environments and a lower corruption positively impact the domestic credits. In a similar vein, Zhou et al. (2020a), Zhou et al. (2020b) investigated the impact of geopolitical risks on financial development using a sample of 18 emerging economies. Their founding suggested that GPR has a negative impact on the private sector's credit.

In a nutshell, empirical evidence is rather limited and overly inconclusive. Against this background, this paper aims to shed more light on the extent to which the effect of geopolitical risk (GPR) has influenced return dynamics and volatility transmission in the turbulent region of the MENA region.

\subsection{Geopolitical risks and stock market return}

Most of this previous research has focused primarily on local political uncertainties, such as elections. However, few empirical studies have investigated the relationship between GPR and stock market return. For instance, Caldara and Iacoviello, (2018) used VAR models to confirm that GPR caused a persistence reduction in major macrocosmic indicators in the US economy, such as employment, export, and GDP. Further, they concluded that GPR shocks are transmitted due to a lack of consumer confidence, as well as uncertainty surrounding economic policy. More importantly, GPR was seen as a key determinant of stock prices that produces a significant reduction in stock prices as it increases. The negative impact of GPR on stock returns in 17 advanced economies is documented. However, this response is not consistent across industries in the US; for instance, the stock price of the defence sector reacted positively to political events such as war (Caldara \& Iacoviello, 
2018). Apergis et al. (2018) examined whether assessment of GPR can foretell fluctuations in stock returns and the volatility of 24 global defence companies using a nonparametric causality test. Their findings confirm that GPR is less likely to be a predictor of stock return. However, it does have a significant impact on the future risk profile of those companies, and it did predict realized volatility in half of the defence firms analysed. Similarly, Bouras et al. (2019) examined the impact of GPR on stock returns and volatility from a sample of 18 emerging market economies. While country-specific GPRs have a statistically weak positive effect on stock volatility, a broad measure of global GPR has a statistically stronger impact on stock volatility. However, neither measure has any significant effect on returns. On the other hand, Antonakakis et al. (2017), who explored the effects of conflict and global tension on the oil-stock markets using a VAR-BEKK-GARCH model, found that the return and variability of the oil market index are significantly affected by the geopolitical tension index, but this is not the case for the stock market index. Another study by Alqahtani et al. (2020) evaluates the in-sample and out-of-sample performance of global GPR and Saudi GPR and crude oil returns in predicting GCC stock returns. Their findings confirm that both Global GPRs and Saudi country-specific political risk have a weak evidence of in-sample predictability of excess stock returns in GCC countries, while the global GPRs show greater prediction in two stock markets, namely Kuwait and Oman, using out-of-sample forecasting.

Zhou et al. (2020a), Zhou et al. (2020b) examine the impact of GPRs on the stock returns and volatility of China's rare metals (RM) in the short term. GPRs have a positive impact on the stock returns of China's RM before 2012, but this impact seems to be negative afterwards. However, the impact of GPRs on the stock volatility are negative before and after 2012. Recently, Smales (2021) investigated the relationship between GPRs and oil price and stock market volatility. The finds confirms an increase in GPRs is associated with positive oil returns, while it has a negative effect on stock. A dynamic conditional correlation (DCC) model shows a persistence volatility in both oil and stock markets in short- and long-term.

Hoque and Zaidi (2020) argues that the relationship between GPRs and stock returns might be nonlinear. Therefore, they use a three-regime Markov-switching approach to examine nonlinear effects of GPRs on stock returns using a sample of five emerging economies. The global GPRs shows both positive and negative impact on stock market performance but this depends on time, lag time, volatility regimes, and stock market. However, country-specific political risk reveal a negative impact on the performance of stock market across volatility regimes.

\section{Data sources and descriptive analysis}

To investigate the impact of geopolitical instability on stock market return and volatility in the MENA countries, we collected data daily on MENA stock markets from May 31, 2005 to May 31, 2018 from DataStream database. The data on GPR was retrieved from the Geopolitical Risk website. ${ }^{2}$ The sample period and countries were determined by the availability of subject data in the countries under investigation. The resulting sample contained

$\overline{2}$ Available [Online]: https://www2.bc.edu/matteo-iacoviello/gpr.htm. 
3392 daily observations in 11 MENA countries ${ }^{3}$-Bahrain, Egypt, Jordon, Kuwait, Morocco, Oman, Qatar, KSA, Tunisia, the UAE, and Lebanon. ${ }^{4}$ These countries provide a representative sample of developed and emerging stock markets in the MENA region, and include both GCC and non-GCC countries. The data on GPR and events comes from Caldara and Iacoviello (2018), who recently developed a news-based index of geopolitical risks, known as the GPR index. This index is constructed using an automated text-search of articles in 11 leading newspapers. ${ }^{5}$ It calculates the number of articles addressing geopolitical tensions and related risks (e.g., wars, terrorism, and tensions between states) in those leading 11 newspapers. Next, the number of articles mentioning geopolitical tensions is divided by the total number of news articles and normalised to an average of 100 .

We believe that this index helps us to provide a more accurate description and analysis of the impact of geopolitical risks on stock returns and volatility in MENA countries, as well as allowing for a particular focus on the effects of geopolitical instability and the Arab Spring.

Table 1 provides statistics and a correlation matrix for GPR and stock returns. As can be seen from panel A (Table 1), the GPR index has an average of 94.96, while stock returns for all MENA markets have an average around zero. Based on standard deviation results, the stock returns of Egypt, KSA, and the UAE exhibit high volatility compared with other markets. All series exhibit Leptokurtic distribution and are negatively skewed, except for GPR in Tunisia and Lebanon, which are positively skewed. The results have been confirmed by Jarque-Bera test statistics, which show that none of the variables under consideration are normally distributed at the $1 \%$ significance level. Results of an ERS unit root test indicate that all series are stationary at that level. Moreover, Ljung-Box test statistics for standard residuals and squared standardized residuals, as well as the Lagrange Multiplier test, reject the null hypothesis of no serial correlation in all series at lag 20. Finally, by looking at the correlation matrix in panel B (Table 1), we can see that stock returns in all cases are independent from the GPR index where all correlation coefficients are approximately zero. There are weak correlations among stock markets in MENA countries except for the UAE and Oman. To some extent, the UAE is positively correlated with Oman, Qatar, and KSA, whereas Oman is positively connected with Qatar.

\section{Empirical methodology}

Our empirical analysis consists of two stages. In the first stage, the standard Dynamic Conditional Correlation (DCC-GARCH) model of Engle (2002) and the Asymmetric Dynamic Conditional Correlation (ADCC-GARCH) model of Cappiello et al. (2006) are utilised to estimate conditional correlations between underlying variables and to capture stylized facts pertaining to stock returns in the MENA region, such as volatility clustering, asymmetric

\footnotetext{
3 "Although MENA region has 21 countries, the inclusion of only 11 MENA countries in our sample is driven by the availability of data".

4 The data that support the findings of this study are available from the corresponding author upon reasonable request.

5 These newspapers are "the Boston Globe, the Chicago Tribune, The Daily Telegraph, the Financial Times, The Globe and Mail, The Guardian, the Los Angeles Times, The New York Times, The Times, The Wall Street Journal, and the Washington Post” Caldara and Iacoviello (2018, p6).
} 


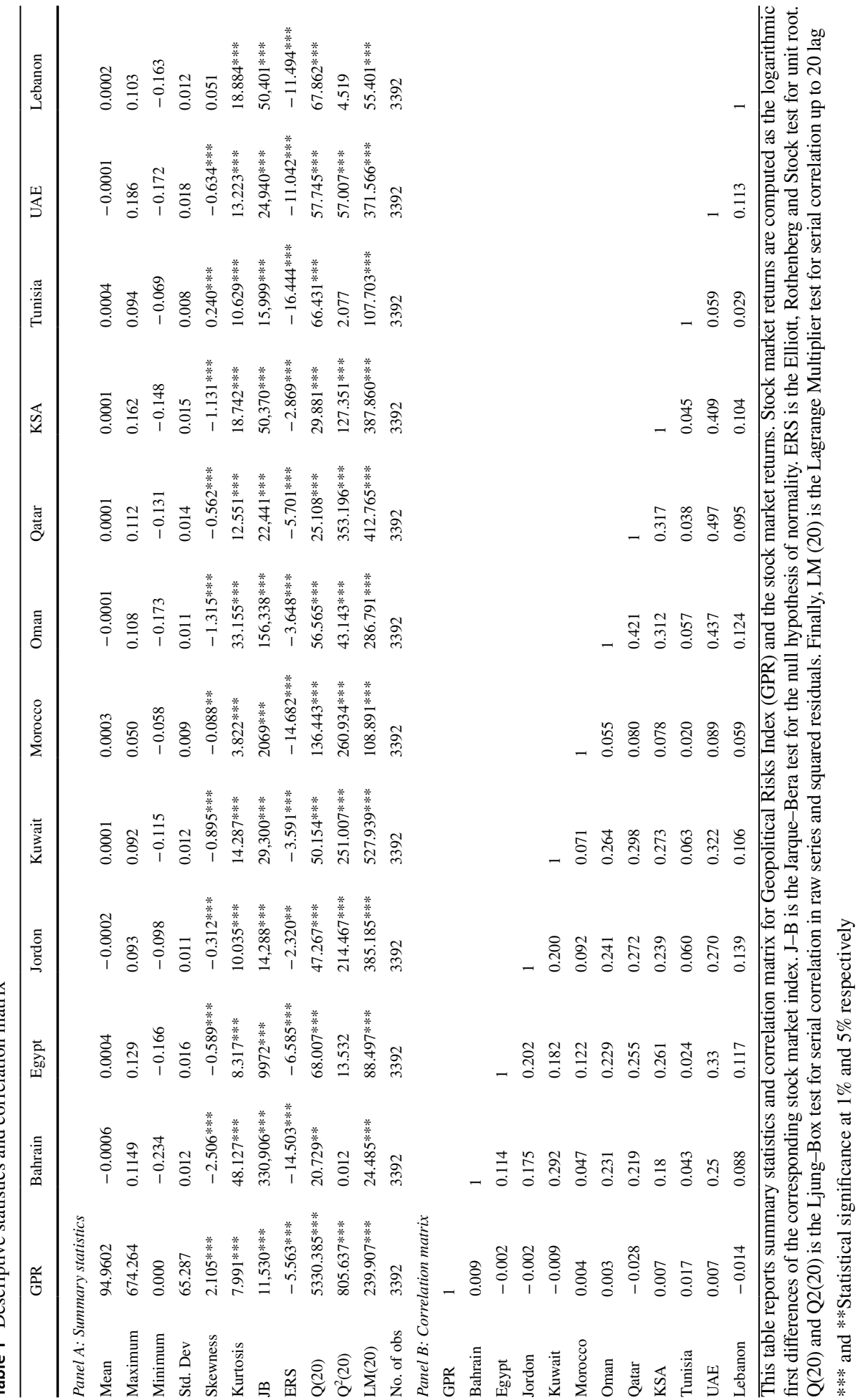


volatility, and time variations. ${ }^{6}$ Secondly, financial connectedness and the impact of GPR on returns dynamics among MENA countries are examined using the spillover approach recently developed by Diebold and Yilmaz (2012, 2015).

\subsection{Modelling dynamics conditional correlations}

The DCC-GRACH model developed by Engle (2002) estimated in two stages. In the first stage, GARCH parameters for each individual variable are calculated. Consequently, the conditional correlations are estimated among variables under consideration. Let the mean equation of a stock return defined as an $\mathrm{AR}(1)$ process be in the form of:

$$
r_{t}=\mu+\varphi r_{t-1}+\varepsilon_{t}
$$

where $r_{t}$ is a $n \times 1$ vector of MENA stock returns, which is conditional on the information set $I_{t-1}, \mu$ is the conditional mean vector of $r_{t}$, and $\varepsilon_{t}$ is a vector of residuals, which are modelled as:

$$
\varepsilon_{t}=H_{t}^{1 / 2} z_{t}
$$

where $z_{t}$ is a $n \times 1$ vector of random error terms that are i.i.d, and $H_{t}$ is an $n \times n$. conditional variance-covariance matrix of $r_{t}$, which could be written as:

$$
H_{t}=D_{t} R_{t} D_{t}
$$

where $D_{t}$ is the diagonal matrix of time-varying conditional standard deviations and $R_{t}$ represents the conditional correlatiomatrix such that:

$$
\begin{gathered}
D_{t}=\operatorname{diag}\left(h_{1, t}^{\frac{1}{2}}, \ldots h_{n, t}^{\frac{1}{2}}\right) \\
R_{t}=\operatorname{diag}\left(q_{1, t}^{-\frac{1}{2}}, \ldots q_{n, t}^{-\frac{1}{2}}\right) \mathrm{Q}_{t} \operatorname{diag}\left(q_{1, t}^{-\frac{1}{2}}, \ldots q_{n, t}^{-\frac{1}{2}}\right)
\end{gathered}
$$

where the conditional variance $\left(h_{i, t}\right)$ is estimated from a univariate $\operatorname{GARCH}(1,1)$ process as follows:

$$
h_{i, t}=\omega_{i}+\alpha_{i} \varepsilon_{i, t-1}^{2}+\beta_{i} h_{i, t-1}
$$

where $\omega_{i}$ is the constant, $\alpha_{i}$ denotes the ARCH term, and $\beta_{i}$ refers to the GARCH component.

In the second stage, the estimated conditional standard deviations and $\varepsilon_{i, \mathrm{t}}$ residuals from Eq. (1) are used to estimate the standardized residual matrix $\phi_{i, t}\left(\phi_{i, t}=\frac{\varepsilon_{i, t}}{\sqrt{h_{i, t}}}\right)$, which in turn is utilised to calculate the symmetric dynamic conditional correlation matrix $\left(Q_{t}\right)$ as:

\footnotetext{
${ }^{6}$ Conditional correlations are estimated based on DCC-GARCH and Asymmetric DCC-GARCH models. To conserve space, we have presented and discussed findings only of the ADCC-GARCH model, which allows us to capture volatility clustering and the asymmetric features of conditional correlations. Henceforward, the results of the DDC-GARCH model are not reported but are available upon request.
} 


$$
Q_{t}=\left(1-\theta_{1}-\theta_{2}\right) \bar{Q}+\theta_{1} \phi_{t-1} \stackrel{\prime}{\phi}_{t-1}+\theta_{2} Q_{t-1}
$$

where $\bar{Q}$ is unconditional variance covariance matrix of the standardised residuals $\phi_{i, t}$ and $\theta_{1}$ and $\theta_{2}$ are positive scalars such that $\theta_{1}+\theta_{2}<1$ to ensure that the DCC model is mean reverting. Finally, the pairwise dynamic conditional correlation between variables $i$ and $j$ is calculated as: $\rho_{i, j, t}=\frac{q_{i, j, t}}{\sqrt{q_{i, i, t}} q_{j, j, t}}$.

Nevertheless, the DCC-GARCH model does not take account of asset-specific news and/or asymmetries in parameters (Kenourgios, 2014). Building on the asymmetric GARCH model introduced by Glosten et al. (1993), Cappiello et al. (2006) introduced the ADCC model in which an asymmetric term is included as follows:

$$
h_{i, t}=\omega_{i}+\alpha_{i} \varepsilon_{i, t-1}^{2}+\beta_{i} h_{i, t-1}+d_{i} \varepsilon_{i, t-1}^{2} I\left(\varepsilon_{i, t-1}\right)
$$

The indicator function, $I\left(\varepsilon_{i, t-1}\right)$, has a value of one if the argument between brackets is true, and zero otherwise. This representation is very important and takes into account one of the key characteristics of financial assets, "leverage effect", where a negative shock has a more profound impact on a financial asset's return and volatility compared with a positive shock of the same magnitude. To this end, the ADCC matrix $\left(Q_{t}\right)$ is calculated as:

$$
Q_{t}=\left(1-\theta_{1}-\theta_{2}\right) \bar{Q}-\gamma \bar{N}+\theta_{1} \phi_{t-1} \stackrel{\prime}{\phi}_{t-1}+\theta_{2} Q_{t-1}+\gamma \eta_{t-1} \stackrel{\prime}{\eta}_{t-1}
$$

where $\theta_{1}, \theta_{2}$ and $\gamma$ are scalar parameters, and the $\gamma$ coefficient represents the asymmetric effect of negative innovations on the conditional correlation. $\bar{N}=E\left[\eta_{t} \eta_{t}\right]$ is the covariance matrix of $\eta_{t} ; \eta_{t}=I\left[\phi_{\mathrm{t}}<0\right]$ o $\phi_{\mathrm{t}}$ where $I\left[\phi_{\mathrm{t}}<0\right]$ is an indicator function that takes value 1 if the residuals are negative, and 0 otherwise, and $\bigcirc$ denotes the Hadamard product. $\bar{Q}$ represents the unconditional covariance matrix of $\phi_{t}$.

\subsection{Spillover approach}

Connectedness and volatility transmission are examined based on a generalized Vector Autoregression (VAR) framework of Koop et al. (1996), and Pesaran and Shin (1998) approach. This method produces a variance decomposition matrix that is invariant to the ordering of variables in the VAR model. Following Diebold and Yilmaz (2014, 2015), and assuming a covariance stationary $\operatorname{VAR}(\mathrm{p})$ of N-variables, the moving average representation can be written as:

$$
y_{t}=\sum_{j=0}^{\infty} A_{j} \varepsilon_{t-j}
$$

where $A_{j}$ are $N \times N$ coefficient matrices that obey a recursion of the form $A_{j}=\Phi_{1} A_{i-1}+\Phi_{2} A_{i-2}+\cdots+\Phi_{p} A_{j-p}$ with $\Phi_{i}$ represent $N \times N$ autoregressive coefficient matrices, $A_{0}$ is $N \times N$ identity matrix and $A_{j}=0$ for all $j<0$. Applying the GVAR framework, the associated $\mathrm{H}$-step-ahead generalized forecast-error variance decomposition function can be expressed as: 


$$
\theta_{i j}^{g}(H)=\frac{\sigma_{j j}^{-1} \sum_{h=0}^{H-1}\left(\dot{\mathrm{e}}_{i} A_{h} \sum e_{j}\right)^{2}}{\sum_{h=0}^{H-1}\left(\mathrm{e}_{i} A_{h} \sum \hat{\mathrm{A}}_{h} e_{i}\right)}
$$

where $\Sigma$ denotes the variance matrix of the vector of errors $\varepsilon_{t}, \sigma_{j j}$ is the $j$ th diagonal element of covariance matrix $\Sigma$ and $e_{i}$ is the selection vector, with one for the $j$ th element and zero otherwise. Since the sum of variance decomposition for each variable is not equal to one under the generalized variance decomposition approach, each entry of the variance decomposition matrix should be normalized by its row sum as follows:

$$
\check{\theta}_{i j}^{\mathrm{g}}(H)=\frac{\theta_{i j}^{\mathrm{g}}(H)}{\sum_{j=1}^{N} \theta_{i j}^{\mathrm{g}}(H)}
$$

With $\sum_{j=1}^{N} \check{\theta}_{i j}^{\mathrm{g}}(H)=1$ and $\sum_{i, j=1}^{N} \theta_{i j}^{\mathrm{g}}(H)=N$ by construction. Consequently, the total aggregation of the variance decomposition across all markets to the total forecast error variance represents the total connectedness index as follows:

$$
C(H)=\frac{\sum_{i, j=1, i \neq j}^{N} \check{\theta}_{i j}^{\mathrm{g}}(H)}{\sum_{i, j=1}^{N} \check{\theta}_{i j}^{\mathrm{g}}(H)} \times 100=\frac{\sum_{i, j=1, i \neq j}^{N} \check{\theta}_{i j}^{\mathrm{g}}(H)}{N} \times 100
$$

The above representation of the variance decomposition matrix is very useful as it allows us to measure directional, as well as pairwise, spillover across markets at horizon $\mathrm{H}$ and, hence, determine whether a given market is a net transmitter or receiver of shocks. For instance, the total directional connectedness from all other markets to market $j$ is estimated as:

$$
C_{j \longleftarrow .}(H)=\frac{\sum_{j=1, j \neq i}^{N} \breve{\theta}_{j i}^{\mathrm{g}}(H)}{\sum_{i, j=1}^{N} \breve{\theta}_{j i}^{\mathrm{g}}(H)} \times 100=\frac{\sum_{j=1, j \neq i}^{N} \breve{\theta}_{j i}^{\mathrm{g}}(H)}{N} \times 100
$$

Similarly, the total spillover effects transmitted from market $j$ to all other markets is computed as:

$$
C_{\cdot \leftarrow j}(H)=\frac{\sum_{j=1, j \neq i}^{N} \check{\theta}_{i j}^{\mathrm{g}}(H)}{\sum_{i, j=1}^{N} \check{\theta}_{i j}^{\mathrm{g}}(H)} \times 100=\frac{\sum_{j=1, j \neq i}^{N} \check{\theta}_{i j}^{\mathrm{g}}(H)}{N} \times 100
$$

Thus, the net directional spillovers index is defined as follows:

$$
C_{j}=C_{\cdot \leftarrow j}(H)-C_{j \leftarrow \cdot}(H)
$$

Finally, directional spillover measures could be decomposed further to analyse the bivariate spillover connectedness between $i$ and $j$ markets as follows:

$$
C_{j i}=C_{i \leftarrow j}(H)-C_{j \leftarrow i}(H)
$$

The value of the net pairwise spillover index indicates whether a market is a net receiver or a net transmitter of shocks, where positive or negative values imply a net transmitter, or a net receiver, of spillovers. 

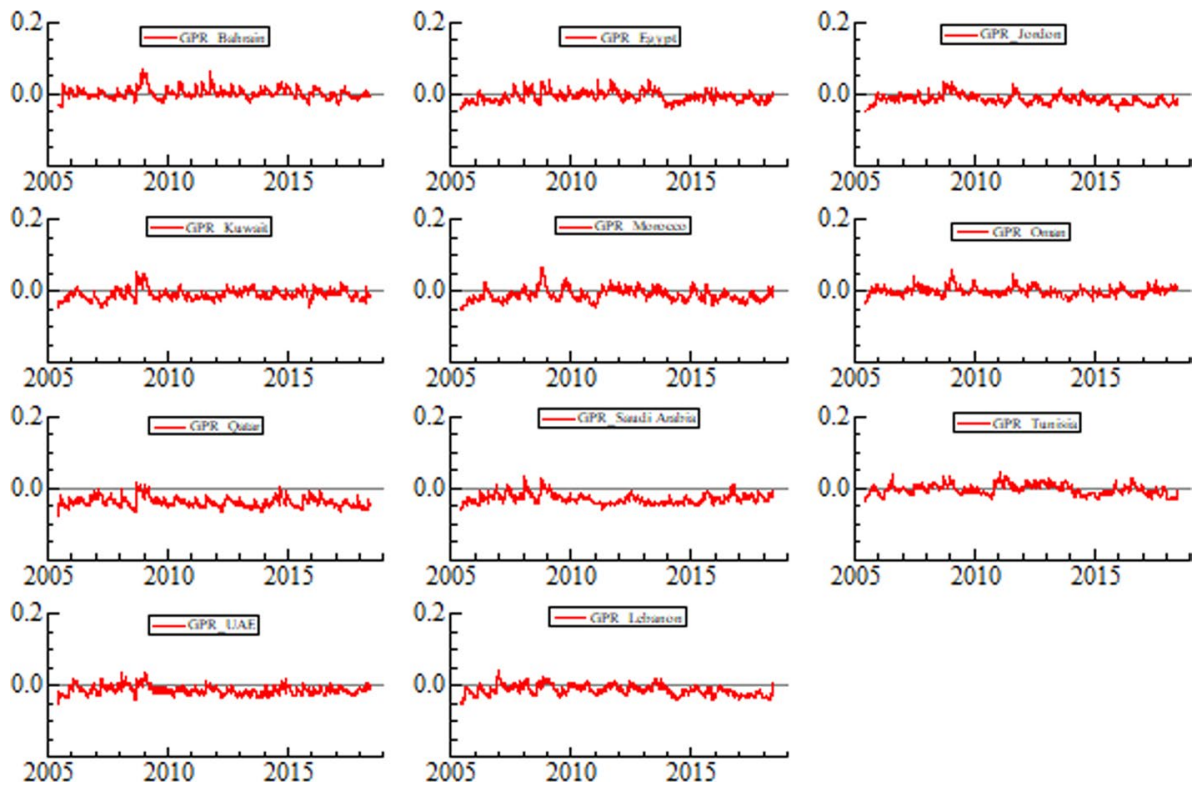

Fig. 1 Dynamic conditional correlations between GPR and MENA stock markets. Note: This diagram displays the time varying pairwise conditional correlation estimates between the GPR and the return of each MENA stock markets over the sample period (31/5/2005-31/5/2018). The conditional correlations estimates have been calculated based on Asymmetric Dynamic Conditional Correlation (AGDCC-GARCH) model developed by Cappiello et al. (2006)

\section{Empirical results and discussion}

This section outlines our findings obtained from the estimations using the ADCC-GARCH model.

\subsection{ADCC-GARCH results}

We began by estimating the conditional correlation between the GPR index and stock markets in MENA economies. For ease and clarity of presentation, we divided empirical results from the ADCC-GARCH model into four parts: (a) correlation between GPR and stock return in all countries in our sample; (b) correlation among GCC stock markets as a group (Bahrain, Kuwait, Oman, Qatar, KSA, and the UAE); (c) correlation between OtherMENA stock markets as a group (Egypt, Jordan, Morocco, Lebanon, and Tunisia); and, finally (d) correlation between GCC and Other-MENA stock markets.

The conditional correlation between GPR and stock return in all MENA countries in our sample over the period, May 31, 2005 to May 31, 2018 is reported in Fig. 1. The evidence shows that there is very weak or no correlation between the GPR index and individual stock returns. For instance, the correlation coefficient is close to zero in most countries in our sample. Moreover, the conditional pairwise correlation among the GCC stock markets group in Fig. 2 also show a weak correlation, although it does seem to be slightly higher between the UAE on the one hand, and Qatar, Oman, and KSA on the other. In 

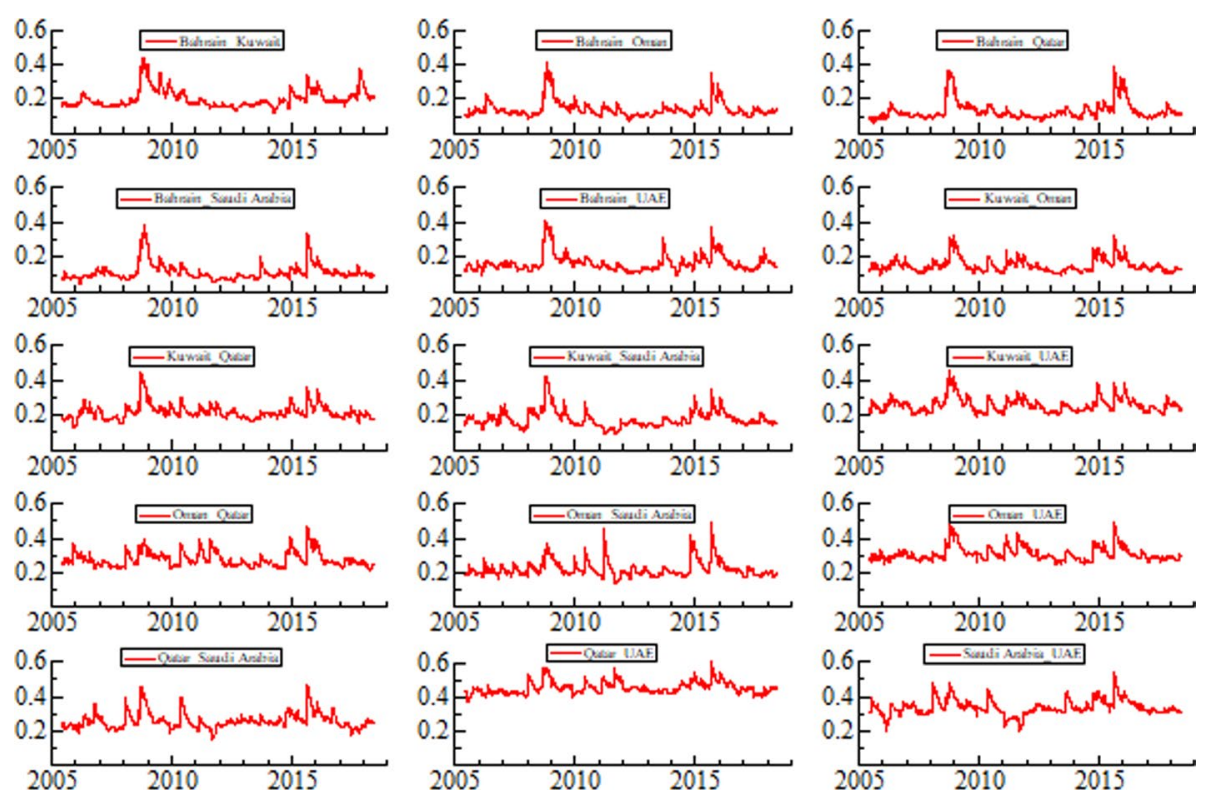

Fig. 2 Dynamic conditional correlations among GCC stock markets. Note: This diagram displays the time varying pairwise conditional correlation estimates between the return of each pair of GCC stock markets over the sample period (31/5/2005-31/5/2018). The conditional correlations estimates have been calculated based on Asymmetric Dynamic Conditional Correlation (AGDCC-GARCH) model developed by Cappiello et al. (2006)

addition, a pattern of high correlation is noticeable during the recent global financial crisis in 2007-2008 and the political tension between Qatar and other GCC countries, ${ }^{7}$ ranging between 0.30 and 0.45 .

Figure 3 provides evidence of a very weak correlation among the Other-MENA stock markets group (Egypt, Jordan, Morocco, Lebanon, and Tunisia). The dynamic conditional correlation between stock market returns in Egypt with Jordan, Morocco, and Lebanon fluctuates between 0.1 and 0.2. Further, such an ADCC-GARCH conditional correlation is almost zero between Tunisia and the other countries (Egypt, Morocco, Jordan, and Lebanon). Last, the results of the asymmetric dynamic conditional correlation between GCC and Other-MENA stock markets indicate that Other-MENA economies and GCC counties are not fully integrated, showing a very weak correlation. However, Jordan and Egypt show more connection with GCC countries compared to other MENA countries (see Fig. 4).

\footnotetext{
7 Three GCC countries, the UAE, Saudi Arabia, and Bahrain withdrew their diplomats from Qatar on March 5, 2014. Further, in June 2017, those same countries suspended all transport links with Qatar and gave two weeks' notice for all Qatari residents in the GCC to return to Qatar. These countries considered Qatar as a threat to other GCC countries, accusing Qatar of providing financial support to terrorist groups (Al-Maadid et al., 2019).
} 

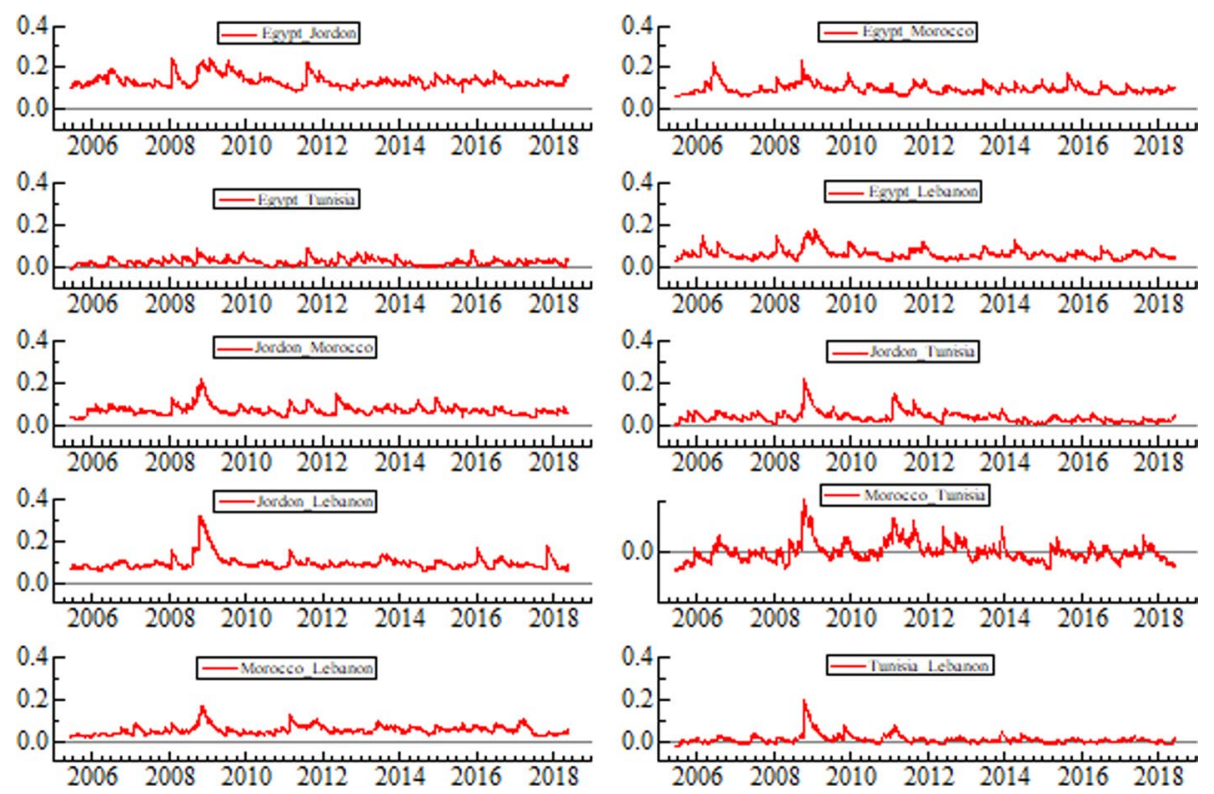

Fig. 3 Dynamic conditional correlations among Other-MENA stock markets. Note: This diagram displays the time varying pairwise conditional correlation estimates between the return of each pair of MENA stock markets except for GCC countries over the sample period (31/5/2005-31/5/2018). The conditional correlations estimates have been calculated based on Asymmetric Dynamic Conditional Correlation (AGDCCGARCH) model developed by Cappiello et al. (2006)

\subsection{Spillover analysis}

Estimates of conditional correlation could be biased as they generally depend on the state of market volatility. Forbes and Rigobon (2002) demonstrated that markets tend to be more correlated during episodes of stress, without any actual changes in interconnections between them. For this reason we extended our analysis by applying the spillover approach introduced by Diebold and Yilmaz $(2014,2015)$. This technique is based on the Forecast Error Variance Decomposition (FEVD) function from a generalized Vector Autoregressive Model (VAR) and, hence, is independent of ADCC conditional correlation estimates (Maghyereh et al., 2015). Firstly, we investigated results from the return static spillover analysis over the full-sample period, followed by an exploration of return dynamic spillover using a 200-day rolling window.

\subsubsection{Static spillover return analysis}

Table 2 reports the findings for the static return spillover analysis based on a VAR model of order two and 10-day FEVD in which ijth item presents the contribution to FEVD of market ith caused by shocks to market $j$. The intra-market spillovers (ownvariance) is represented by the diagonal of the FEVD matrix $(i=j)$, whereas the intermarket spillovers (cross-variance) are shown in the off-diagonal elements $(i \neq j)$. The net 


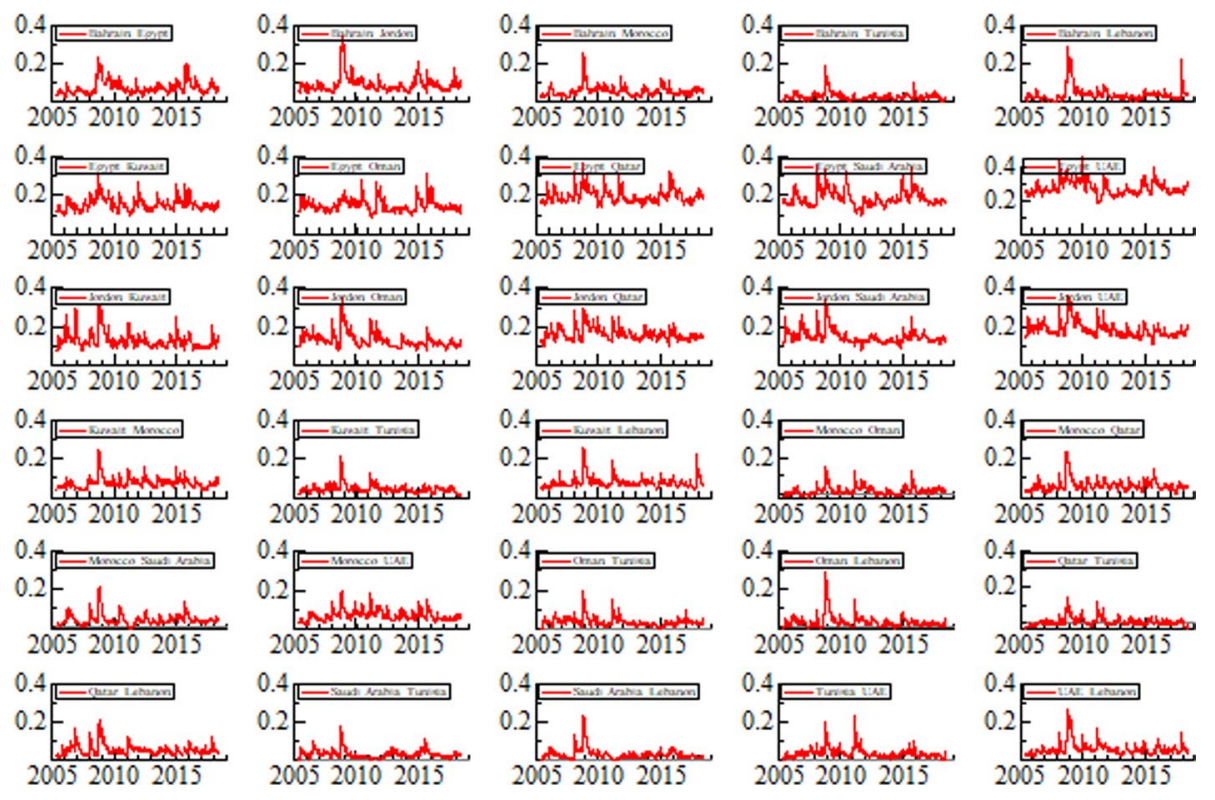

Fig. 4 Dynamic conditional correlations between GCC and Other-MENA stock markets. Note: This diagram displays the time varying pairwise conditional correlation estimates between the return of each pair of GCC and Other-MENA stock markets over the sample period (31/5/2005-31/5/2018). The conditional correlations estimates have been calculated based on Asymmetric Dynamic Conditional Correlation (AGDCCGARCH) model developed by Cappiello et al. (2006)

contribution, presented in the last row, was calculated as the difference between contribution to others and contribution from others.

It is evident that the main contributor to the forecast FEVD is intra-market return spillovers, shown in the diagonal, compared to the off diagonal ones. For instance, over $90 \%$ of shocks are explained by intra-market return spillover in Morocco, Tunisia and Lebanon, while this accounts for around 50\% in Oman, Qatar and the UAE. These findings are confirmed by the gross directional return spillovers measures in which the contribution of the former countries is less than the latter. More specifically, the contribution to other markets from Morocco, Tunisia, and Lebanon are 4\%, 1.8\%, and 7.7\% respectively. On the other hand, KSA, Oman, Qatar and the UAE are the main contributors to other markets, accounting for $39.6 \%, 42.7 \%, 48 \%$, and $62.9 \%$ respectively.

Further, our findings indicate that the GCC markets are more connected with each other when compared to other MENA markets in our sample. This is made clear from the inter-market spillover (Table 2). In the case of stock market returns in Qatar, $12.12 \%, 9.29 \%, 6.25 \%$, and $5.69 \%$ of the forecast-error variance are explained by shocks in the UAE, Oman, KSA, and Kuwait respectively. ${ }^{8}$ This means that $36.65 \%$ of the forecast-error variance for stock market returns in Qatar is transmitted from other GCC countries, while only $8.6 \%$ comes from the other MENA countries in our sample. The economy of the GCC countries has similar characteristics, all depending mainly

${ }^{8}$ However, the contribution from Bahrain is very weak, accounting for $3.3 \%$. 
Fig. 5 Directional pairwise spillovers network. Note: Directional connectedness network shows the pairwise directional return spillovers among all possible pairs of our variables where node's colour implies whether a variable is a net transmitter/receiver of spillovers with red colour presents net transmitter and green colour shows net receivers. In addition, thickness and the colour of the arrows denote the magnitude and strength of the spillover effect between each pair where red indicates strong and green refers to weak return spillovers

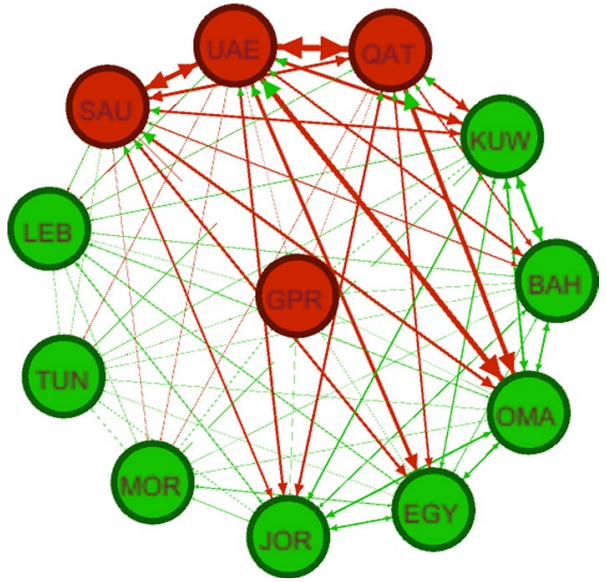

on oil revenue. Further, Ahmed (2011) found a high level of market interconnectedness among GCC markets. Further, Al-Maadid et al. (2019) confirm that the political tensions between Qatar and other GCC countries on June 2017 lowered stock market returns and increased the level of volatility spillovers within the GCC region. The total return spillover index shows that, on average, $25.9 \%$ of volatility spillover is from cross-market connectedness. These findings are consistent with those of Elsayed and Yarovaya (2019), Antonakakis et al. (2017), Chiang et al. (2017) and Damianov and Elsayed (2018).

Given our study's focus on the impact of geopolitical events on stock market return and volatility in MENA countries, another significant finding is that the GPR index shows a statistically very weak effect on stock returns. GPR accounts for less than $0.5 \%$ of the forecast-error variance in all countries in our sample. This finding is in line with those obtained by Bouras et al. (2019), who found that GPR had no significant effect on returns using a panel GARCH approach for 18 emerging market economies. The MENA region is historically unstable and has been marred by several political and geopolitical conflicts, which might have already been discounted in the stock returns (Antonakakis et al., 2017). Further, the stock market in MENA countries is not well connected or integrated with the international financial market. Neaime (2016) investigated the contagion vulnerability and the international and regional financial linkages of MENA stock markets using a Vector Error Correction Model (VECM). He found that no cointegrating vector between GCC stock markets and the world's major stock markets in the US, the United Kingdom, and France.

In addition, estimations of net directional spillover, Eq. (16), are used to determine the net receivers and transmitters of volatility among the MENA stock markets. This helps us to determine both the main receivers and transmitters of shocks over the sample period.

It is evident from Fig. 5, net-pairwise directional connectedness, and Table 2 that there is a weak connection between GPR and stock return in individual MENA economies. Further, it is obvious that the UAE, KSA, and Qatar are the main transmitters of volatility to other GCC countries, as well as Egypt and Jordan. These latter two countries seem to be more integrated with the GCC countries. 


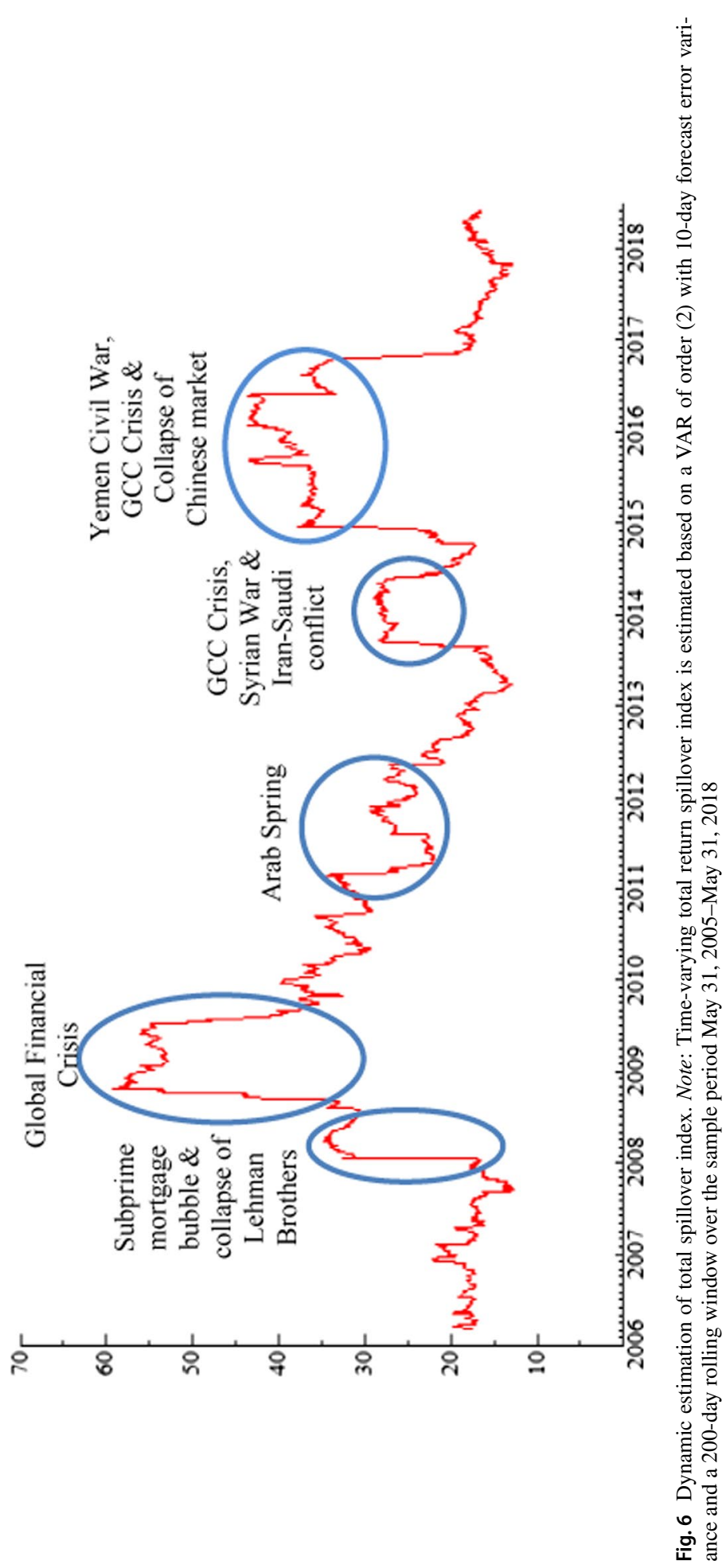



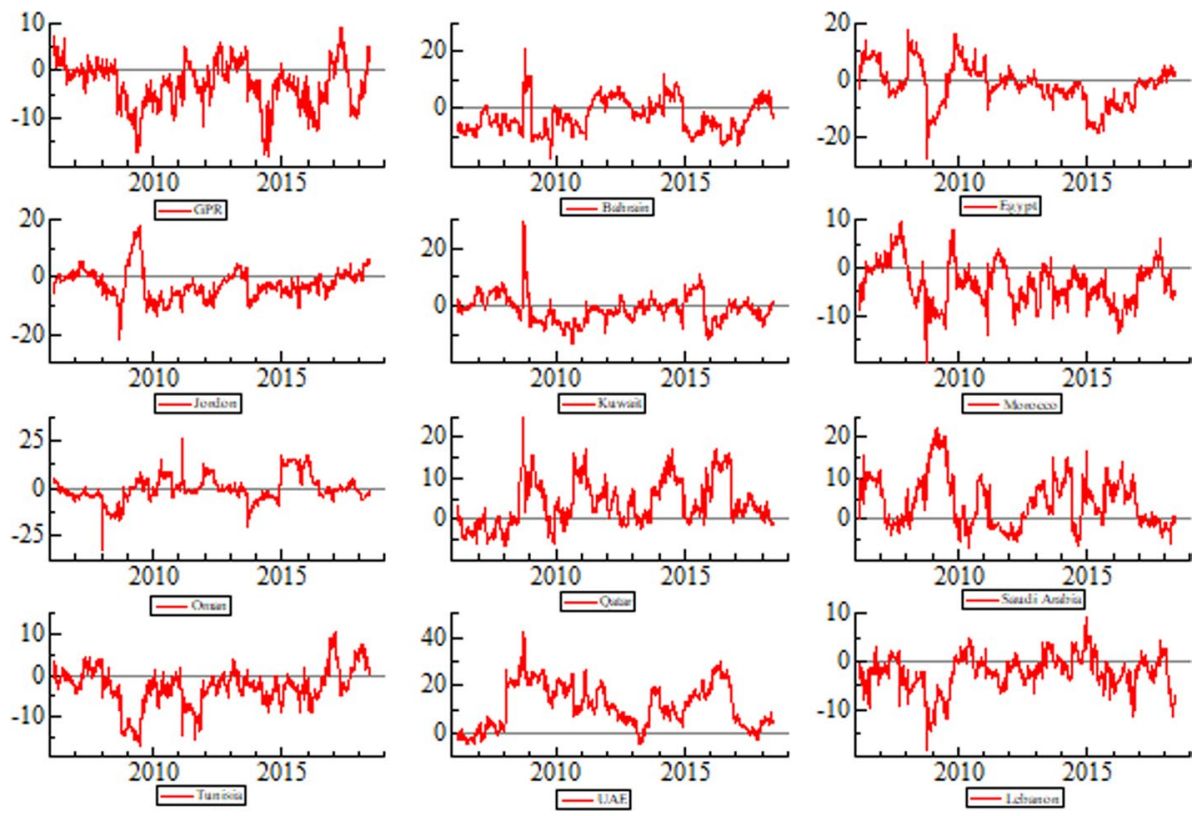

Fig. 7 Net directional spillovers indices. Note: these time-varying directional spillover indices have been estimated using a daily VAR model of order 2 with 10-step ahead forecasts and a 200-day rolling windows. The horizontal axis presents the sample period (31/5/2005-31/5/2018) whereas the vertical axis indicates the magnitude of net spillover index

\subsubsection{Dynamic spillover analysis}

The static spillover return index shows the overall average contribution to and from other markets over the entire sample. However, it does not show how connectedness and risk transmission evolve over time. Furthermore, it masks the impact of volatility caused by political and financial turbulence on intensity and the direction of spillovers across financial markets in MENA economies. To overcome these shortcomings, a dynamic volatility spillover index is estimated over a 200-day rolling window and 10-day forecast horizon for a variance decomposition matrix. The dynamic analysis in Fig. 6 shows that the timevarying total spillover index is very responsive to political and economic turmoil in which one can observe a high degree of volatility during the sample period. For instance, spikes and volatility in total return spillovers are associated with the recent 2008 financial crisis, the Arab Spring uprising in 2010/2011, which started in Tunisia and spread to other MENA regimes, Egypt, Libya and Syria, the war against ISIS, and the Yemen Civil War (2015-present).

Figure 7 shows the dynamic net directional return spillover. Three countries in the GCC, Qatar, KSA, and the UAE are the main transmitters of return spillovers to the rest of the MENA countries. This is consistent with the findings of Bouri and Yahchouchi (2014), who concluded that UAE and KSA exercise substantial influence on volatility spillover into other MENA markets probably due to their relative large equity market. On the other hand, Bahrain, Egypt, Jordan, Morocco, Tunisia, and Lebanon are the major receivers of return spillovers. The dynamic of spillover transmission varies over time. For example, Kuwait, 

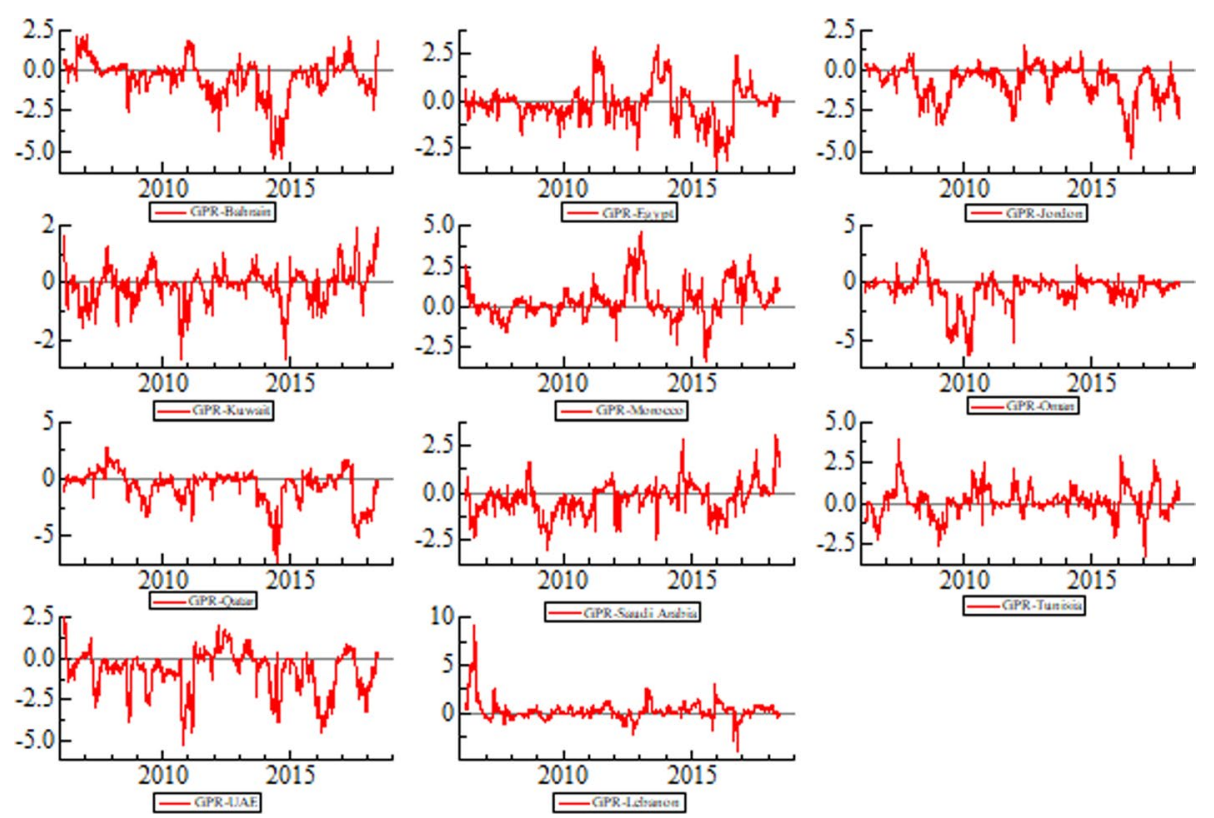

Fig. 8 Net pairwise spillovers among GPR and MENA stock markets. Note: these dynamic net pairwise spillover indices have been estimated using a daily VAR model of order 2 with 10-step ahead forecasts and a 200-day rolling windows. The horizontal axis presents the sample period (31/5/2005-31/5/2018) whereas the vertical axis indicates the magnitude of net pairwise spillover index

Bahrain, and Jordan switch from being transmitter countries during the recent global financial crisis and political turmoil during the Arab Spring. Surprisingly, Tunisia and Egypt, both of which faced political uprisings in 2011, do not appear to be spreaders of any shock to the rest of the region during the Arab Spring. However, the Tunisian stock market, in particular, is very insular given weak trade relations and is not well connected with the rest of MENA countries (Bouri \& Yahchouchi, 2014).

\subsubsection{Net pairwise spillover}

Apart from examining the return spillover among MENA countries, our paper takes a step further to investigate this relationship including the GPR index. We focus on net pairwise spillover between the GPR index and stock return volatility. The findings are presented in Fig. 8, where positive and negative values of the net pairwise index indicate that the GPR index is a net transmitter, and receiver, of shock to and from market $i$. Overall, Fig. 8 shows that the GPR index is not the key net transmitter of spillovers to most financial markets in MENA countries. This confirms the findings in Table 1 and Fig. 5. However, this is not the case for Tunisia, where the financial market has been a net receiver of GPR shock since the uprising in the country in 2011. One important finding is that only regional GPR events, such as the start of the Arab Spring and the escalation in the wars in Syria, and against ISIS, are the drivers of volatility return spillovers in Egypt and Morocco (Table 2). Further, the recent political tension between Qatar and 


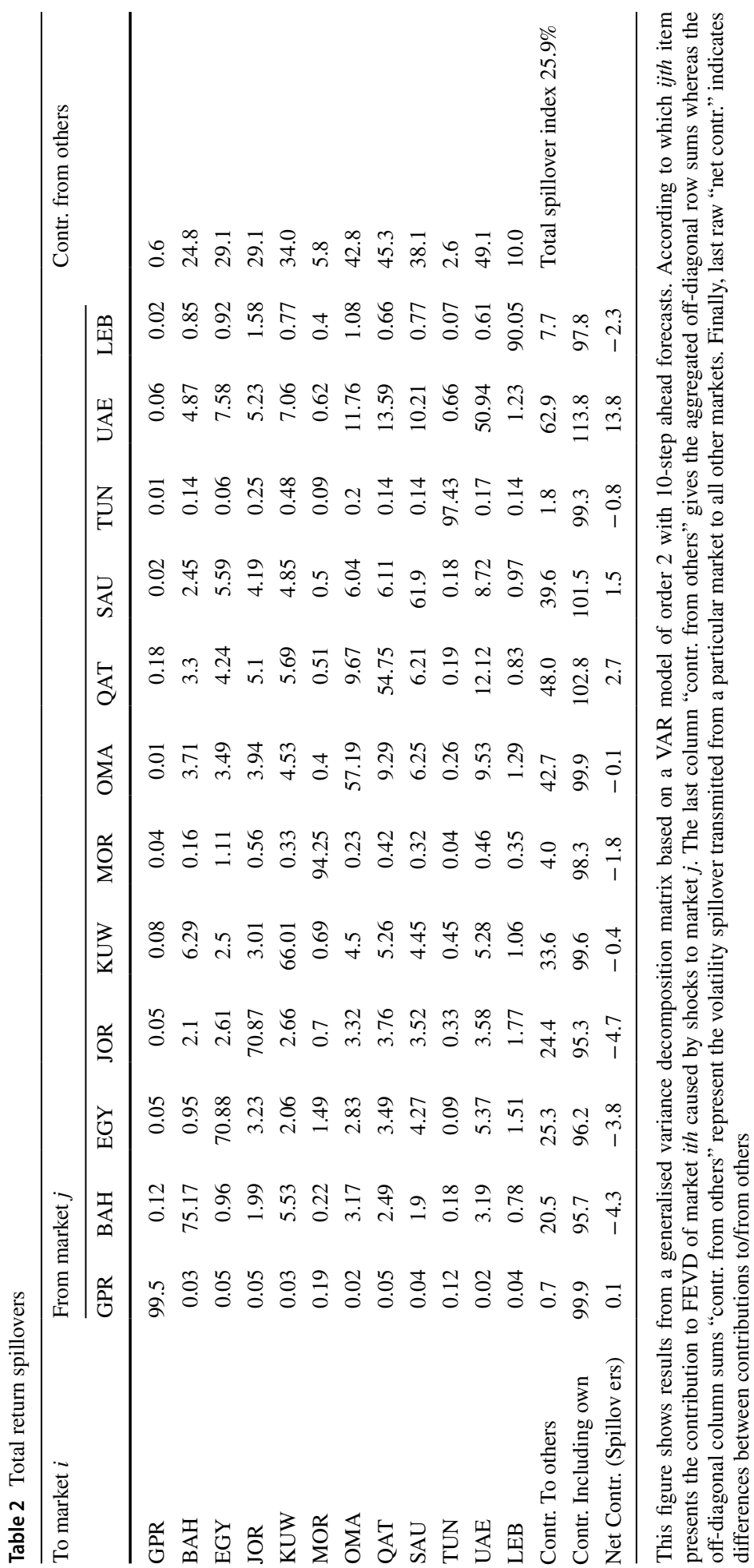


rest of the GCC countries in 2017 shows that GPR is the net transmitter of stock return spillovers in Bahrain, Kuwait, and KSA in post 2017 events (see Fig. 8).

\section{Conclusion}

This paper has examined how MENA financial markets are integrated between themselves, and sheds light on the key driving forces behind dynamic co-movement, with particular focus on the effects of GPR on return and volatility transmissions in MENA countries. Those countries depend on natural resources and have comparable economic structures, rapid population growth, underdeveloped financial markets and similar political systems. The period of the study runs from May 31, 2005 to May 31, 2018 for 11 MENA countries.

Although this region has experienced high levels of political conflicts since the uprising in 2011 (Chau et al., 2014), the lack of empirical studies in the literature is surprising. Therefore, this empirical paper is a contribution to fill this gap. Contrary to previous literature, it focuses on the impact of GPR on financial interconnectedness among MENA countries. In particular, the inclusion of the GPR index allowed us to investigate whether MENA and GCC countries are affected by national risk, as well as geopolitical turbulence around the globe. For this reason, the ADCC-GARCH model of Cappiello et al. (2006), in addition to the spillover methodology proposed by Diebold and Yilmaz $(2009,2012)$, were employed. Moreover, a rolling window was used to examine both static and dynamic analysis.

Our extensive analysis indicates that the GPR index does not contribute to the return spillovers in MENA and GCC countries. However, the GPR index is a net transmitter of spillovers to Bahrain, Kuwait, and KSA during major political events such as the Arab Spring uprising in 2010/2011, the Yemen Civil War, the global financial crisis in 2008, as well as recent political tension between Qatar and other GCC countries. Our findings show that there is a weak correlation and volatility transmission among MENA countries but the GCC markets are more connected with each other. Qatar, KSA, and the UAE are the main transmitters of return spillovers to the rest of MENA markets. Surprisingly, Tunisia and Egypt, both of which faced political uprisings in 2011, do not appear to be spreaders of any shock to the rest of the region during the Arab Spring.

Our paper has limitations related to the adopted methodology. Despite the fact that the spillover approach of Diebold and Yilmaz provides evidence of volatility transmission and spillover in time domain, it does not provide any information on volatility transmission across financial market at different investment horizon in the MENA region (e.g., spillover in short-run and long-run investment horizon).

Overall, our findings are crucial to policymakers, market regulators, portfolio managers, and investors to learn more about the role of geopolitical risks on spillover among MENA countries, and provide policy implications. As GPR shocks are largely unpredicted, policymakers and regulators in MENA countries should improve significantly the resilience of their fragile financial markets to enhance financial stability. Investors in this region can mitigate the impact of spillover effects among MENA markets by holding a diversified portfolio including local and international financial assets.

Supplementary Information The online version contains supplementary material available at https://doi. org/10.1007/s10479-021-04081-5. 
Open Access This article is licensed under a Creative Commons Attribution 4.0 International License, which permits use, sharing, adaptation, distribution and reproduction in any medium or format, as long as you give appropriate credit to the original author(s) and the source, provide a link to the Creative Commons licence, and indicate if changes were made. The images or other third party material in this article are included in the article's Creative Commons licence, unless indicated otherwise in a credit line to the material. If material is not included in the article's Creative Commons licence and your intended use is not permitted by statutory regulation or exceeds the permitted use, you will need to obtain permission directly from the copyright holder. To view a copy of this licence, visit http://creativecommons.org/licenses/by/4.0/.

\section{References}

Al-Maadid, A., Caporale, GM., Spagnolo, F. and Spagnolo, N. 2019. Political Tension and Stock Markets in the Arabian Peninsula. International Journal of Finance and Economics. ISSN: 1076-9307

Alexakis, P., \& Petrakis, P. (1991). Analysing stock market behaviour in a small capital market. Journal of Banking and Finance, 15, 471-483

Alqahtani, A., Bouri, E., \& Vo, X. V. (2020). Predictability of GCC stock returns: The role of geopolitical risk and crude oil returns. Economic Analysis and Policy, 68, 239-249

Antonakakis, N., Gupta, R., Kollias, C., \& Papadamou, S. (2017). Geopolitical risks and the oil-stock nexus over 1899-2016. Finance Research Letters, 23, 165-173

Apergis, N., Bonato, M., Gupta, R., \& Kyei, C. (2018). Does geopolitical risks predict stock returns and volatility of leading defense companies? Evidence from a nonparametric approach. Defence and Peace Economics, 29(6), 684-696

Balcilar, M., Bonato, M., Demirer, R., \& Gupta, R. (2018). Geopolitical risks and stock market dynamics of the BRICS. Economic Systems, 42(2), 295-306

Bouras, C., Christou, C., Gupta, R., \& Suleman, T. (2019). Geopolitical Risks, Returns, and Volatility in Emerging Stock Markets: Evidence from a Panel GARCH Model. Emerging Markets Finance and Trade, 55(8), 1841-1856

Bouri, E. I., \& Yahchouchi, G. (2014). Do return and volatility traverse the Middle Eastern and North African (MENA) stock markets borders? Journal of Economic Studies, 41(2), 317-344

Caldara, D., \& Iacoviello, M., 2018. Measuring Geopolitical Risk (No. 1222). Board of Governors of the Federal Reserve System (US).

Cappiello, L., Engle, R. F., \& Sheppard, K. (2006). Asymmetric Dynamics in the Correlations of Global Equity and Bond Returns. Journal of Financial Econometrics, 4, 537-572

Chan, Y., \& Wei, K. C. J. (1996). Political risk and stock price volatility: the case of Hong Kong. PacificBasin Finance Journal, 4, 259-275

Chau, F., Deesomsak, R., \& Wang, J. (2014). Political uncertainty and stock market volatility in the Middle East and North African (MENA) countries. Journal of International Financial Markets, Institutions and Money, 28, 1-19

Chesney, M., Reshetarb, G., \& Karamana, M. (2011). The impact of terrorism on financial markets: an empirical study. Journal of Banking and Finance, 35(2), 253-267

Damianov, D. S., \& Elsayed, A. H. (2018). On the transmission of spillover risks between the housing market, the mortgage and equity REITs markets, and the stock market. Finance Research Letters, 27, 193-200

Diebold, F. X., \& Yilmaz, K. (2009). Measuring financial asset return and volatility spillovers, with application to global equity markets. The Economic Journal, 119(534), 158-171

Diebold, F. X., \& Yilmaz, K. (2012). Better to give than to receive: Predictive directional measurement of volatility spillovers. International Journal of Forecasting, 28(1), 57-66

Diebold, F. X., \& Yilmaz, K. (2014). On the network topology of variance decompositions: Measuring the connectedness of financial firms. Journal of Econometrics, 182, 119-134

Diebold, F. X., \& Yilmaz, K. (2015). Trans-Atlantic Equity Volatility Connectedness: U.S. and European Financial Institutions, 2004-2014. Journal of Financial Econometrics, 14, 81-127

Dogan, E., Majeed, M. T., \& Luni, T. (2021). Analyzing the impacts of geopolitical risk and economic uncertainty on natural resources rents. Resources Policy, 72, 102056

Elsayed, A. H., \& Yarovaya, L. (2019). Financial stress dynamics in the MENA region: Evidence from the Arab Spring. Journal of International Financial Markets, Institutions and Money, 62, 20-34 
Engle, R. (2002). Dynamic Conditional Correlation. Journal of Business \& Economic Statistics, 20, $339-350$

Forbes, K., \& Rigobon, R. (2002). No contagion, only interdependence: Measuring stock market comovements. Journal of Finance, 57, 2223-2261

Gilpin, R. and Gilpin, J.M., 2001. Global political economy: Understanding the international economic order. Princeton University Press.

Glick, R., \& Taylor, A. M. (2010). Collateral damage: Trade disruption and the economic impact of war. The Review of Economics and Statistics, 92(1), 102-127

Glosten, L. R., Jagannathan, R., \& Runkle, D. E. (1993). On the relation between the expected value and the volatility of the nominal excess return on stocks. The journal of finance, 48, 1779-1801

Gozgor, G. (2018). Determinants of the domestic credits in developing economies: The role of political risks. Research in International Business and Finance, 46, 430-443

Hoque, M. E., \& Zaidi, M. A. S. (2020). Global and country-specific geopolitical risk uncertainty and stock return of fragile emerging economies. Borsa Istanbul Review, 20(3), 197-213

Kenourgios, D. (2014). On financial contagion and implied market volatility. International Review of Financial Analysis, 34, 21-30

Koop, G., Pesaran, M. H., \& Potter, S. M. (1996). Impulse response analysis in nonlinear multivariate models. Journal of econometrics, 74(1), 119-147

Liu, L. X., Shu, H., \& Wei, K. J. (2017). The impacts of political uncertainty on asset prices: Evidence from the Bo scandal in China. Journal of financial economics, 125(2), 286-310

Maghyereh, A. I., Awartani, B., \& Hilu, K. A. (2015). Dynamic transmissions between the U.S. and equity markets in the MENA countries: New evidence from pre- and post-global financial crisis. The Quarterly Review of Economics and Finance, 56, 123-138

Neaime, S. (2016). Financial crises and contagion vulnerability of MENA stock markets. Emerging Markets Review, 27, 14-35

O’Sullivan, A., Rey, M. E., \& Mendez, J. G. (2011). Opportunities and Challenges in the MENA Region. Arab world competitiveness report, 2012, 42-67

Pástor, L, \& Veronesi, P. (2013). Political uncertainty and risk premia. Journal of Financial Economics, $110(3), 520-545$

Perotti, E. C., \& Oijen, P. V. (2001). Privatization, political risk and stock market development in emerging economies. Journal of International Money and Finance, 20(1), 43-69

Pesaran, H. H., \& Shin, Y. (1998). Generalized impulse response analysis in linear multivariate models. Economics letters, 58(1), 17-22

Smales, L. A. (2021). Geopolitical risk and volatility spillovers in oil and stock markets. The Quarterly Review of Economics and Finance, 80, 358-366

Zhou, L., Gozgor, G., Huang, M., \& Lau, M. C. K. (2020a). The Impact of Geopolitical Risks on Financial Development: Evidence from Emerging Markets. Journal of Competitiveness, 12(1), 93

Zhou, M. J., Huang, J. B., \& Chen, J. Y. (2020b). The effects of geopolitical risks on the stock dynamics of China's rare metals: A TVP-VAR analysis. Resources Policy, 68, 101784

Publisher's Note Springer Nature remains neutral with regard to jurisdictional claims in published maps and institutional affiliations. 